\title{
Comunicação alternativa para alunos com Autismo no ensino regular
}

\author{
Cátia Crivelenti de Figueiredo Walter* \\ Leila Regina d'Oliveira de Paula Nunes**
}

Resumo

O presente artigo descreve uma das etapas de um projeto de Comunicação Alternativa para alunos com autismo no contexto escolar na rede municipal de ensino, do Rio de Janeiro. Tem como objetivos relatar e discutir as necessidades e os desejos dos professores que atuam nas salas de recursos oferecendo o AEE - Atendimento Educacional Especializado, e que participam do processo de inclusão de alunos com autismo. Os professores receberam um curso de formação teórico-prático sobre o emprego do PECS-Adaptado, um sistema de Comunicação Alternativa que funciona por intercâmbio de figuras e é especialmente destinado a tal alunado. Os participantes foram questionados, ao final do curso, sobre suas necessidades e seus anseios relativos à utilização desse recurso em sala de aula, na escola regular. Os resultados mostraram que a maioria dos professores apresenta intenção de se comunicar melhor com seus alunos, expressando, contudo, necessidade de suporte de professores especializados e participação ativa de todos os envolvidos no processo de inclusão. Consideraram ainda que a Comunicação Alternativa deve ser introduzida inicialmente na sala de atendimento especializado e, posteriormente, na sala de aula regular.

Palavras-chave: PECS adaptado; Formação de professores; Inclusão.

* Professora Doutora da Universidade do Estado do Rio de Janeiro, Rio de Janeiro, Rio de Janeiro, Brasil.

** Professora Doutora da Universidade do Estado do Rio de Janeiro, Rio de Janeiro, Rio de Janeiro, Brasil. 


\title{
Alternative communication for students with Autism in regular schools
}

\begin{abstract}
The paper describes a stage of a research project about Alternative Communication for students with autism in metropolitan schools classrooms in Rio de Janeiro. The purposes of the study were both to report and to discuss the needs and desires of elementary school teachers who work in the resource rooms offering specialized educational service and participating of the inclusion process of students with autism. Teachers attended to a theoretical-practicum course about the use of adapted PECS, an Alternative Communication system that functions by the exchange of pictures, and is specially tailored for students with autism. By the end of the course, the participants were asked about their needs and desires related to the employment of this resource in the regular classroom. The results showed that the majority of the teachers presents intention for better communication with their students, expressing, nonetheless, the need for both support from specialized teachers and the active participation of all people involved with the inclusion process. The participants considered that Alternative Communication should be introduced first in the resource rooms and later on in the regular classroom, as well.
\end{abstract}

Keywords: Adapted PECS; Teacher training; Inclusion.

\section{Introdução}

A linguagem, uma das mais significativas aquisições na vida de uma criança, é compreendida como um sistema simbólico construído socialmente e governado por regras que servem prioritariamente ao propósito da comunicação. Determinante da constituição do sujeito e de sua inserção sociocultural, a linguagem se destaca como elemento crítico na aquisição de outros sistemas simbólicos como a leitura e a escrita (WARREN, KAISER, 1988, NUNES, 1992), e é a via na qual, com a qual e sobre a qual se estabelecem as relações entre as pessoas e destas com a cultura (WALTER, NUNES, 2008).

Encontramos, todavia, indivíduos que, por comprometimentos cognitivos, motores ou emocionais, são incapazes de desenvolver linguagem oral ou de utilizála de forma funcional para fins comunicativos. Nesta população especial, figuram as pessoas com autismo. É patente que as dificuldades na linguagem e na comunicação, que afetam um indivíduo nos primeiros anos de vida, possam trazer danos significativos ao seu desenvolvimento global. Com efeito, o prejuízo linguístico no autismo envolve dificuldades não apenas na comunicação não verbal, mas também nos processos simbólicos, nos aspectos pragmáticos da linguagem (PRIZANT et al., 2000), nas habilidades que a precedem, na produção e na compreensão da fala e no uso de gestos simbólicos e de mímicas (PERISSINOTO, 2003; TOMAZELO, 2003; VON TETZCHNER et al., 2004). 
Além dos distúrbios na linguagem, o autismo, síndrome que afeta um em cada 350 brasileiros (PAULA et al., 2011), se caracteriza igualmente pela limitada capacidade interativa, atenção deficitária, pelo repertório restrito e estereotipado de interesses e de atividades e por padrões atípicos de comportamento (NUNES et al., 2007; WALTER, NUNES, 2008; WALTER, TOGASHI, LIMA, 2011). Ao considerar o déficit de comunicação e os distúrbios de conduta como sintomas presentes e marcantes no quadro de autismo, seria lógico raciocinar que estes estão, na maioria das vezes, relacionados entre si. É muito provável que a ausência ou dificuldade grave em se comunicar e interagir com o outro provoque nesses indivíduos com autismo exibição de condutas agressivas, inadequadas e estereotipadas dirigidas às pessoas com quem convivem (WALTER, ALMEIDA, 2010).

Bosa (2006), ao analisar a literatura sobre intervenções utilizadas com pessoas diagnosticadas dentro do espectro do autismo, ressalta que, frequentemente, ao enfrentar um diagnóstico de Transtorno Invasivo do Desenvolvimento - TGD, as famílias tendem a especular sobre que tipo de intervenção psicoeducacional é a mais efetiva. Assim, pesquisas acerca da inclusão de alunos em ambientes escolares são altamente recomendadas. Ainda que em número escasso, algumas delas trazem dados muito relevantes. Desse modo, destacamos aqui as de Gomes e Mendes (2010), Correa Netto (2012) e Nunes e Gomes (no prelo). A análise do processo de inclusão de alunos com autismo em Belo Horizonte, conduzida por Gomes e Mendes (2010), mostrou que nenhum tipo de adequação da metodologia de ensino e dos conteúdos pedagógicos foi relatado pelos professores. Do mesmo modo, os alunos com autismo não falantes, não faziam uso dos recursos de Comunicação Alternativa. Foi destacada, ainda a alta porcentagem de auxiliares de vida escolar, que pareceu afetar positivamente a frequência dos alunos na escola. Contudo, os alunos com autismo participavam pouco das atividades acadêmicas, sua interação com os colegas era escassa e a aprendizagem de conteúdos pedagógicos limitada.

Correa Netto (2012), em estudo conduzido em escola regular, mostrou que as adaptações pedagógicas, nas quais sejam empregados recursos visuais que favoreçam a compreensão do aluno, são extremamente importantes no processo inclusivo do aluno com autismo. Com efeito, recursos adaptados do Programa Teacch (Treatment and Education of Autistic and Related Communication Handicapped Children) e recursos visuais da Comunicação Alternativa e Ampliada - CAA foram empregados na elaboração de painéis para a turma ou para uso individual a fim de favorecer a autorregulação do aluno com autismo e possibilitar a previsibilidade das atividades a serem realizadas em classe e dos profissionais que estarão presentes. A autora concluiu que a utilização dos procedimentos do ensino/consultoria colaborativa entre professores especiais e regulares pode promover a viabilização de estratégias docentes eficazes, e instigar reflexões e debates sobre como incluir alunos com autismo no ensino regular (WALTER, CORREA NETTO, NUNES, no prelo).

Nunes e Gomes (no prelo) avaliaram os efeitos de um programa de intervenção nas interações comunicativas entre um aluno com autismo e sua professora no contexto da sala de aula regular. Basicamente, a intervenção envolveu 
a capacitação da professora para empregar o Ensino Naturalísticol visando ensinar o aluno-alvo a fazer uso dos recursos da CAA. As autoras concluíram que, após a implementação do programa, as atividades propostas pela professora passaram a ser mais bem-adaptadas e realizadas, em grande parte, com o apoio de pictogramas. Como possível consequência da introdução dos recursos de CAA, foi observada melhora qualitativa nas interações estabelecidas pela díade.

Os estudos arrolados acima evidenciam que os programas de intervenção destinados às pessoas com autismo no ambiente escolar devem focalizar a aquisição da linguagem e da comunicação. Com efeito, em uma avaliação de tais programas, a Comunicação Alternativa e Ampliada foi considerada como prática promissora (SIMPSON, 2005). A CAA envolve um amplo conjunto de recursos, métodos e técnicas que complementa ou substitui a linguagem oral comprometida ou ausente. Uma revisão de artigos científicos, conduzida por Nunes e Nunes Sobrinho (2010), evidenciou a eficácia da CAA para esta população. Dos 56 estudos revisados, 26 empregaram sistemas pictográficos de comunicação e, dentre esses, 13 avaliaram os efeitos do Picture Exchange Communication System - PECS), no desempenho comunicativo de indivíduos com autismo. O PECS é um programa de Comunicação Alternativa por meio de intercâmbio de figuras (BONDY, FROSTY, 1994). Estudos voltados especificamente à avaliação do PECS revelaram que o ensino intensivo para o uso deste recurso de baixa tecnologia favorece não apenas as iniciativas comunicativas, para obter reforçadores tangíveis e não tangíveis, como promove a instalação de repertório comunicativo funcional em muitos indivíduos com autismo (SULZER-AZAROFF et al., 2009). Eles mostraram, contudo, que os ganhos na comunicação não se estendem à fala (FLIPPIN, RESZKA, WATSON, 2010).

Considerando os déficits comunicativos e interacionais, não é difícil perceber que escolarizar alunos com autismo constitui um grande desafio para a educação inclusiva no Brasil. Os documentos oficiais do MEC têm proposto a inserção do aluno com deficiências diversas em salas regulares de ensino e apontado o Atendimento Educacional Especializado - AEE como forma de suporte pedagógico para efetuar tal inclusão. Assim, considerando a dificuldade de comunicação de alunos com autismo, e a constante queixa dos professores a respeito de desconhecimento e falta de preparação para lidar com essa clientela na sala de aula regular, um estudo recente foi realizado, no município do Rio de Janeiro, ${ }^{2}$ com o objetivo de verificar os efeitos do programa de formação de professores da rede pública do município do Rio de Janeiro no emprego da Comunicação Alternativa (PECS-Adaptado) em sala de aula do ensino regular.

\section{Método}

A Secretaria Municipal de Educação do Rio de Janeiro conta com dez Coordenadorias Regionais de Educação - CRE. Cada CRE é responsável por uma área delimitada para atuação. A proposta era capacitar um número razoável de professores, a fim de que eles posteriormente servissem de agentes multiplicadores do conhecimento adquirido e, como tal, formassem outros professores da rede de ensino. Cada CRE fez a indicação de três professores do AEE, que atuavam nas salas de 
recursos multifuncionais, e de um elemento da equipe do Instituto Helena Antipoff - IHA, órgão responsável pela educação especial do município do Rio de Janeiro. Cada professor deveria ter pelo menos um aluno com TGD que não apresentasse fala funcional ou mesmo inteligível. Assim, foi conduzida uma formação dos professores sobre Comunicação Alternativa e o uso do sistema PECS-Adaptado, ${ }^{3}$ com duração de oito meses, de maio a dezembro de 2011.

Os professores dessas salas de recursos multifuncionais foram então, convidados pelo Instituto Helena Antipoff a comparecer a um primeiro encontro para conhecer o projeto e assumir livremente a participação no curso de formação. Foram convidados 40 professores e, destes, 38 compareceram ao primeiro encontro, sendo que 32 professores participaram do curso de forma assídua pelo período de sete meses (maio a dezembro de 2011), em um total de 30 horas. Todos os professores aceitaram livremente participar do projeto e assinaram o Termo de Livre Esclarecimento, assim como autorização de uso das imagens.

A formação dos professores foi realizada no auditório do IHA. Todas as sessões foram filmadas e transcritas para posterior análise e discussão. O conteúdo do curso, de caráter teórico-prático, envolveu alterações de linguagem, Comunicação Alternativa e a aplicação do PECS-Adaptado para alunos com autismo não verbais ou que apresentam fala não funcional. As aulas foram marcadas pela presença, sempre animadora, dos professores, que em todos os encontros traziam questionamentos sobre situações vivenciadas em sala de aula com alunos com autismo que apresentavam dificuldades comunicativas e comportamentos inadequados, com os quais os professores não sabiam como lidar.

No início e ao final do curso foi aplicado um questionário com o propósito de obter informações dos professores acerca da Comunicação Alternativa e de suas necessidades em sala de aula com alunos autistas. Foi ainda aplicado outro questionário, ao final do curso, com o objetivo de conhecer o aproveitamento teórico e prático do professor, o grau de satisfação e quais as atribuições dos professores responsáveis pela aplicação do programa na sala de aula regular e nas salas de recurso. Outra informação importante destacada nas respostas ao questionário final foi relativa ao profissional encarregado da confecção do material, da ampliação do vocabulário utilizado com os alunos, do controle dos registros e da coordenação do programa de Comunicação Alternativa na escola regular.

Após a realização do curso de formação, os dados foram categorizados e dispostos em gráficos com a finalidade de discussão, publicação e apresentação aos professores, gestores e coordenadores da rede municipal do Rio de Janeiro.

\section{Resultados}

A Figura 1 mostra as frequências absolutas das respostas dos professores ao questionário aplicado no início do curso de formação, em que, são descritas as dificuldades encontradas com a presença de alunos com autismo em sala de aula ou nas salas de AEE. 


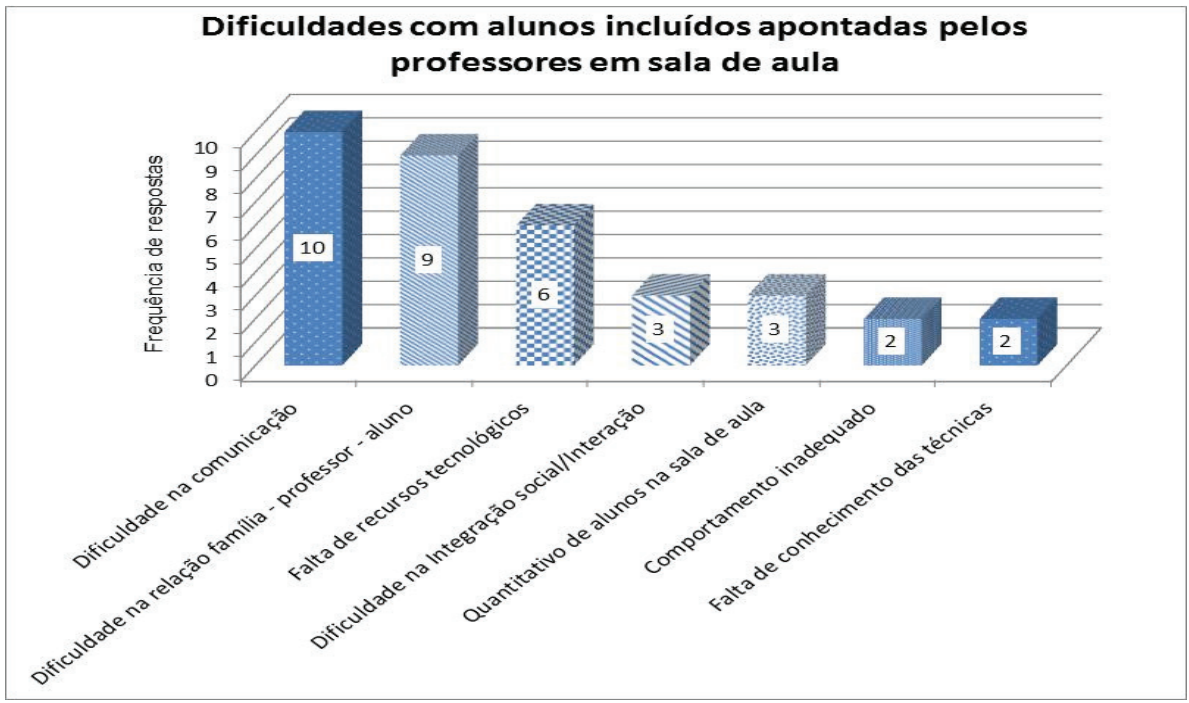

Figura 1. Frequência das respostas sobre as dificuldades apresentadas pelos professores com a presença de um aluno com autismo em sala de aula, ou na sala de AEE.

A figura acima indica que a maioria dos professores apresentou dificuldades referentes à comunicação dos alunos incluídos, ou seja, dificuldades em dialogar, compreender e se fazer entender. Os participantes indicaram ainda, em ordem decrescente: dificuldade na relação família-escola-aluno; falta de recursos tecnológicos; quantidade de alunos em sala de aula; dificuldade na interação social; comportamentos inadequados; falta de conhecimento das técnicas; e outros.

Alguns conceitos sobre a Comunicação Alternativa já eram dominados pelos professores antes mesmo de receberem a formação. Vejamos alguns relatos:

Meio por onde os alunos poderão se comunicar conosco de forma diversificada e diferenciada (Fernanda4).

São vários tipos de materiais que nos possibilitam uma comunicação com aquele que não fala (Patrícia).

Conjunto de recursos que apoia a fala do transmissor e favorece a interpretação do receptor (Neiva).

Forma de comunicação alternativa à fala para possibilitar a interação do sujeito com impedimentos de expressão oral (Tereza).

Foi possível observar que os professores conheciam alguns sistemas de Comunicação Alternativa e valorizavam os recursos como instrumentos importantes na intermediação do diálogo de alunos com dificuldades severas na comunicação oral. Os relatos a seguir confirmam esse conhecimento e valorizam o uso da Comunicação Alternativa como recurso importante no que se refere à autonomia dos alunos: 
Tipo de comunicação diferenciada, a fim de estabelecer uma comunicação no processo de aprendizagem, seja entre professor/aluno ou aluno/aluno (Cristina).

É um meio diferenciado de falar para se comunicar (Gabi).

Uso de alguns instrumentos e estratégias para garantir que o indivíduo se expresse com autonomia (Quênia).

É a libertação de um corpo aprisionado (Wilma).

É o método utilizado para estabelecer comunicação com pessoas que ainda não a desenvolveram (José).

Quando os professores foram questionados sobre a utilização do PECSAdaptado como sistema alternativo de comunicação para alunos com autismo, foi possível observar que eles desconheciam este recurso, mas apresentavam noção sobre sua utilidade, como demonstram os comentários abaixo:

É utilizado para melhorar a relação interpessoal de pessoas com dificuldade na fala (Bia).

Usado para buscar uma comunicação efetiva (Ida).

Utilizado para promover a comunicação, possibilitando a interação social e a expressão dos desejos, necessidades e interesses (Leda).

Para que se supere a ausência de linguagem oral clara e se conquiste uma vida de troca - de comunicação (Bruna).

Os dados coletados, por meio dos questionários, (o questionário final foi respondido por somente 20 participantes) mostraram que, segundo os professores, após o curso de formação eles: aprenderam a trabalhar com Comunicação Alternativa; adquiriram mais conhecimento sobre TGD; conheceram mais uma ferramenta de trabalho para ser utilizada em sala de aula; sentiram mais segurança na prática pedagógica com alunos com dificuldades comunicativas.

Outros aspectos positivos assinalados pelos respondentes foram a apreciação da prática e o conteúdo teórico do curso, com destaque para o novo recurso pedagógico que os professores puderam construir para favorecer a comunicação dos alunos com autismo. Eles ofereceram ainda algumas sugestões como: encontros mais frequentes e mais discussão com professor especializado; cursos práticos para construir novas pranchas, álbuns e painéis de comunicação; além da aprendizagem, de forma dinâmica, para utilização desses recursos em sala de aula, dando continuidade ao processo de formação especializada.

A Figura 2 exibe a frequência absoluta das respostas sobre a viabilidade da aplicação do programa PECS-Adaptado em sala de aula regular. 


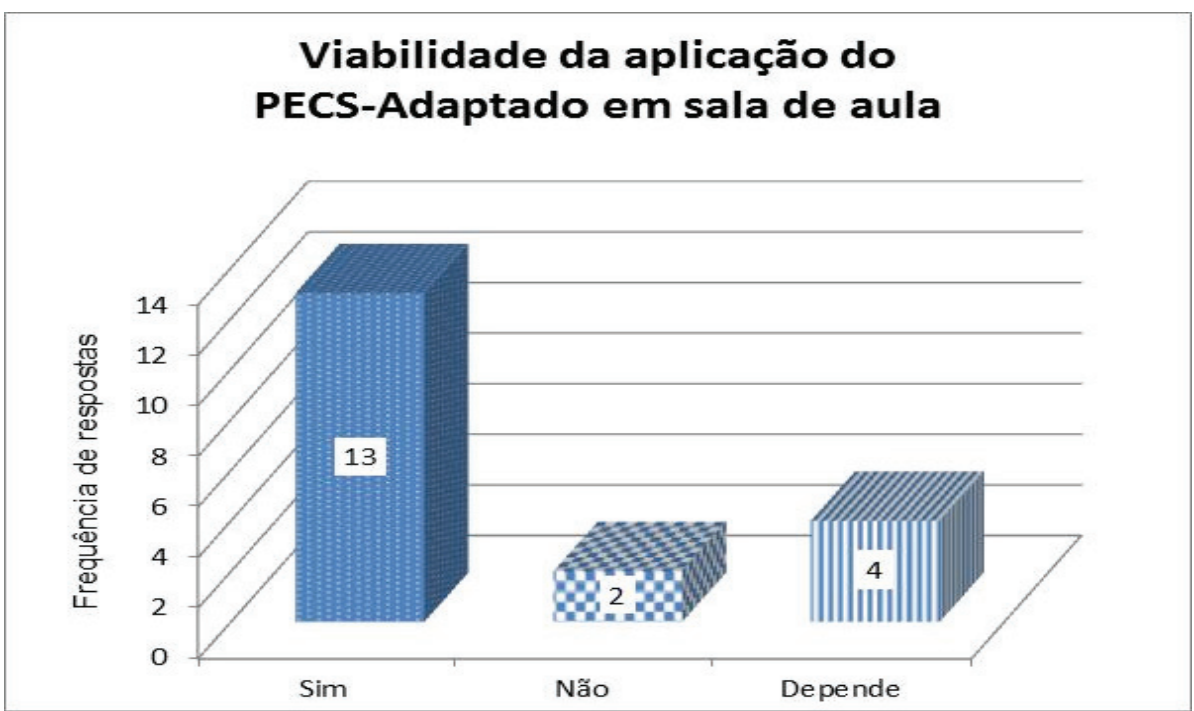

Figura 2. Frequência das respostas sobre viabilidade da aplicação do programa PECS-Adaptado em sala de aula regular.

Conclui-se que a maioria dos professores acredita muito na viabilidade de se utilizar o PECS-Adaptado em sala de aula regular.

A Figura 3 mostra a frequência absoluta de respostas das participantes quanto à responsabilidade pela coordenação do Programa de CAA na escola regular.

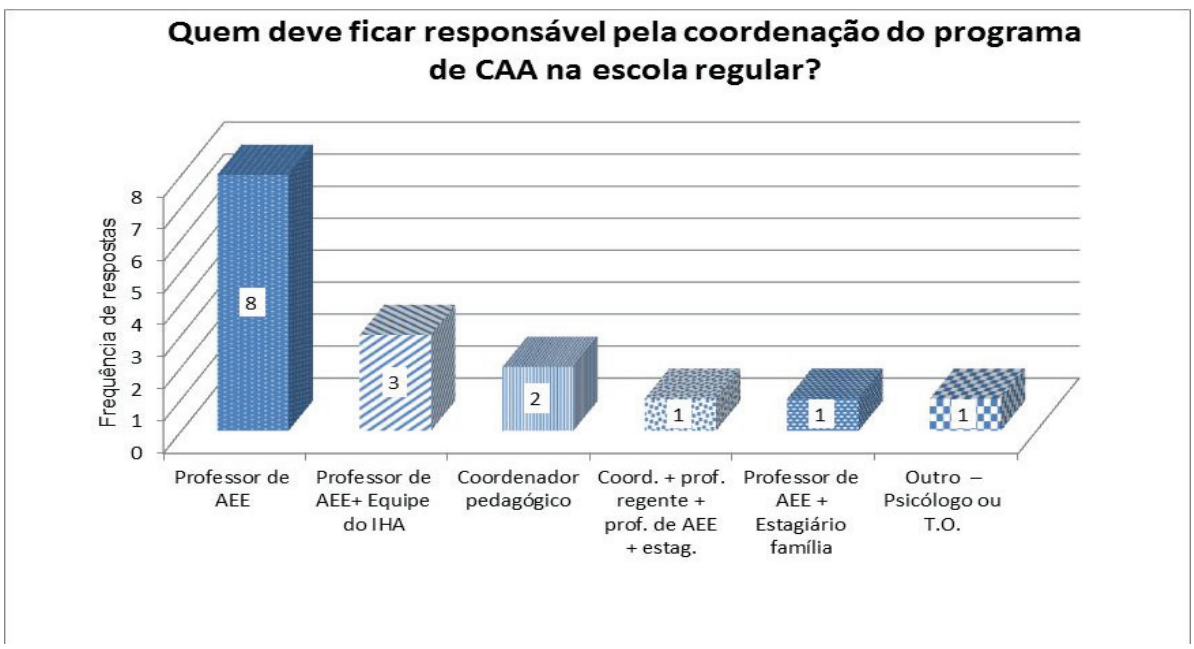

Figura 3. Frequência das respostas sobre responsabilidade para coordenar o programa de CAA na escola regular. 
Os participantes, de forma geral, propuseram que os professores especializados das salas de AEE se responsabilizassem pela coordenação do Programa de Comunicação Alternativa - ProCA na escola regular. Segundo eles, o ProCA dever ser utilizado apenas quando os alunos apresentarem dificuldades severas na fala, inicialmente na sala do AEE e posteriormente, na sala regular. Solicitaram igualmente a diminuição da quantidade de alunos em sala de aula e a reestruturação da sala de aula. Consideraram que o trabalho junto à família deve preceder a implementação do programa na sala de aula regular. Sugeriram ainda, que os professores de sala de aula regular devem adquirir conhecimento prévio sobre o ProCA.

Na Figura 4 é exibida a frequência absoluta de respostas à questão sobre quem deve se responsabilizar pela confecção dos painéis, dos álbuns de comunicação e pela impressão das figuras utilizadas no PECS-Adaptado, ou por qualquer outro recurso de Comunicação Alternativa, assim como pela revisão do vocabulário dos alunos sem fala funcional.

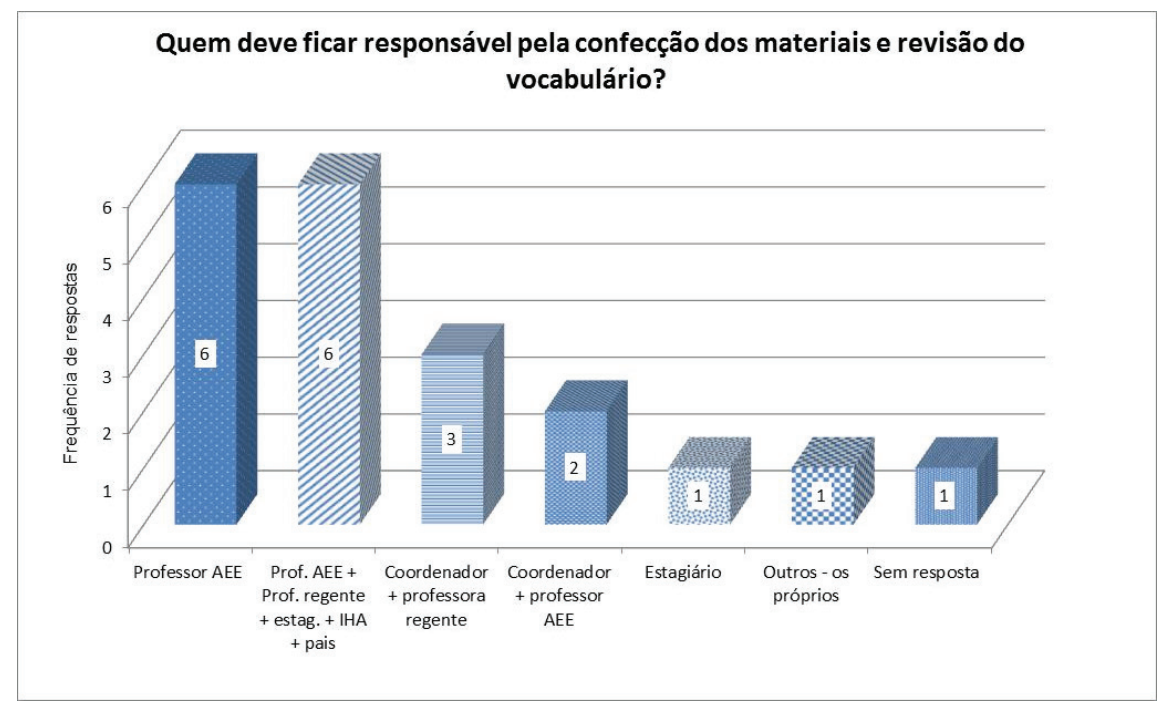

Figura 4. Frequência das respostas sobre responsabilidade pela confecção de materiais do ProCA e revisão do vocabulário dos alunos sem fala funcional na escola regular.

A maioria dos respondentes indicou que a elaboração dos recursos do ProCA, e a revisão do vocabulário dos alunos sem fala funcional, na escola regular deve ficar a cargo dos professores do AEE, envolvendo a participação de estagiários (mediadores), de familiares e de toda a gestão escolar.

Após a implementação do curso de formação, foi verificado maior envolvimento dos professores que atuam diretamente com alunos com autismo. Com efeito, durante o curso, os professores trouxeram casos para discussão em grupo, com o objetivo de melhorar as interações sociais e ampliar a forma de comunicação em sala de aula. Os professores do AEE relataram que procuraram ampliar o envolvimento 
do professor de sala regular, dos estagiários, da família e da unidade escolar, nas discussões e no planejamento das ações, que visassem ao progresso do aluno na comunicação interpessoal e no desempenho acadêmico. Um dado muito interessante foi observado em uma Reunião de Estudos ${ }^{5}$ dos professores da rede municipal, quando três professoras, participantes desse estudo, prepararam uma apresentação sobre o uso da CAA em sala de aula regular e sala de recursos, demonstrando interesse em multiplicar os conhecimentos adquiridos no curso de formação. Essas professoras se propuseram a despertar o interesse de seus pares na utilização da CAA junto a seus alunos sem fala funcional, oferecendo o respaldo teórico necessário para iniciar o trabalho, nas salas de recursos, com a autorização dos familiares e o devido acompanhamento da equipe da Educação Especial do Instituto Helena Antipoff. Vale ressaltar que a atitude das professoras foi voluntária e demonstrou compromisso em compartilhar suas experiências e práticas pedagógicas com seus pares, assumindo o papel de multiplicadores de novos saberes.

\section{Discussão e considerações finais}

A Política Nacional de Educação Especial, na Perspectiva da Educação Inclusiva, garante, desde 2008, o direito de todos os alunos estarem juntos nas escolas, aprendendo e participando, sem qualquer tipo de discriminação. Uma das garantias da Política Nacional é o Atendimento Educacional Especializado, um serviço da Educação Especial que "[...] identifica, elabora e organiza recursos pedagógicos e de acessibilidade, que eliminem as barreiras para a plena participação dos alunos, considerando suas necessidades específicas" (SEESP/MEC, 2008). O AEE complementa e/ou suplementa a formação do aluno, visando sua autonomia na escola e fora dela, constituindo oferta obrigatória pelos sistemas de ensino. Este atendimento é realizado, de preferência, nas escolas comuns, em um espaço físico denominado Sala de Recursos Multifuncional. As funções do professor de Educação Especial devem ficar assim redimensionadas e dirigidas prioritariamente à articulação com as atividades desenvolvidas por professores, coordenadores pedagógicos, supervisores e gestores das escolas comuns, tendo em vista o benefício dos alunos e a melhoria da qualidade de ensino.

Os professores participantes do presente estudo, ao atribuírem a grande responsabilidade da coordenação dos programas de CAA aos professores do AEE, corroboram o discurso oficial do MEC, conferindo a esta função um papel de maior destaque que a do professor regente de sala de aula. Outro fato destacado pelos professores do estudo refere-se à carência de suporte especializado aos professores das salas regulares no processo inclusivo dos alunos com autismo, gerando sentimentos de insegurança e despreparo para planejar e desenvolver atividades pedagógicas em sala de aula. Os achados de Gomes e Mendes (2010) confirmam a precariedade do suporte oferecido aos professores de sala de aula, no estudo conduzido em Belo Horizonte, destacando que entre $40 \%$ e $60 \%$ dos professores entrevistados afirmaram receber apoio do município no formato de orientação ocasional, sendo pouco efetivo e pouco motivador. 
No processo de inclusão escolar para os alunos com Transtorno Global do Desenvolvimento - TGD, observa-se que o atendimento escolar a esta clientela necessita de ajustes e melhorias para que suas necessidades educacionais possam ser supridas satisfatoriamente. Os alunos com autismo apresentam comportamentos bastante peculiares, tornando suas relações, na escola, ainda mais delicadas. Tais condutas são geralmente apontadas pelos professores do ensino regular como fator estressor na sala de aula, dificultando o ensino e elevando o nível de frustração de todos os presentes na sala de aula, especialmente quando o aluno em questão apresenta grande comprometimento na linguagem/comunicação (WALTER, 2011). Com efeito, a literatura nacional e internacional tem sido eloquente, não somente em destacar o sentimento de despreparo desse professor diante de tal desafio (NUNES e GOMES, no prelo; ROBERTSON, CHAMBERLAIN, KASARI, 2003; ALVES, 2005; SERRA, 2008; MELLO, 2004; LIRA, 2004; GOMES E MENDES, 2010), mas também em evidenciar a urgência de uma formação de qualidade para favorecer atitudes positivas a respeito da inclusão desse alunado nas escolas regulares e, sobretudo, desenvolver habilidades para interagir e ensinar esse aluno (RODRIGUEZ, SALDAÑA, MORENO, 2012; FALKMER, PARSONS, GRANLUND, 2012; CORREA NETTO, 2012).

De maneira geral, observa-se uma frequência maior dos alunos com autismo, no ambiente regular de ensino, seja na sala de aula, seja nas salas de AEE, porém os dados sugerem pouca participação desses alunos nas atividades acadêmicas, assim como baixa interação com os colegas (GOMES, MENDES, 2010). Desse modo, alunos com autismo, que apresentam graves dificuldades na comunicação oral e que estão incluídos em escolas de ensino regular necessitam de professores capacitados e comprometidos em favorecer o processo inclusivo e proporcionar, através de recursos e estratégias pedagógicas, a sua efetiva participação no espaço escolar, na ampliação da sua forma comunicativa e na construção de possibilidades significativas de ensinoaprendizagem.

Sistemas de CAA, para promover a comunicação em contexto escolar, têm trazido benefícios a toda a comunidade escolar - alunos, responsáveis, pais e gestão escolar. As diversas investigações envolvendo CAA, no espaço da sala de aula, apontam para melhoria significativa nas práticas pedagógicas, assim como nas relações interpessoais de alunos não oralizados com paralisia cerebral e com autismo (NUNES, AZEVEDO, FREIRE, 2011; SCHIRMER, 2011; SILVA, OLIVEIRA, SILVA, PONTES, 2011; LOURENÇO, 2012; CORREA NETTO, 2012; NUNES, 2009, OLIVEIRA, 2010).

Assim, os resultados apresentados, neste estudo, revelam a importância de ouvir os professores, suas necessidades, e ao mesmo tempo a necessidade de cobrar do poder público uma organização no sistema especializado de ensino, objetivando promover melhor interação entre professores regentes da sala de aula regular e professores especializados que atuam nas salas de AEE. É preciso investigar melhor o ambiente regular de ensino, suas características de funcionamento e a estrutura administrativa, pois as gestões administrativa e pedagógica precisam dialogar e caminhar juntas numa estrada bem-sinalizada, com serviços de apoio teórico e prático aos professores, buscando atingir o alvo comum: melhor formação educacional de 
todos os alunos e consequentemente uma inclusão de qualidade dos alunos com autismo.

\section{Referências}

BRASIL. Política Nacional de Educação Especial. Brasília: MEC/SEESP, 2008.

BONDY, A.; FROST, L. PECS: The Picture Exchange Communication System. Cherry Hill, NJ: Pyramid Educational Consultants, Inc., 1994.

BOSA, C. A. Autismo: intervenções psicoeducacionais. Revista Brasileira de Psiquiatria, v. 28 , p. $47-53,2006$.

CORREAA NETTO, M. M. F. A Comunicação Alternativa favorecendo a aprendizagem de crianças com autismo, Asperger e Angelman: formação continuada de profissionais de Educação e Saúde. Dissertação (Mestrado em Educação) apresentada ao Proped - Programa de Pós-Graduação em Educação, da Universidade do Estado do Rio de Janeiro - UERJ, 2012.

FALKMER, M.; PARSONS, R.; GRANLUND, M. Looking through the same eyes? Do teachers' participation ratings match with ratings of students with autism spectrum conditions in mainstream schools? Autism Research and Treatment, 2012, Article ID 656981, p. 1-13.

FLIPPIN, M.; RESZKA, S.; WATSON, L; R. Effectiveness of the Picture Exchange Communication System (PECS) on Communication and Speech for Children With Autism Spectrum Disorders: A Meta-Analysis. American Journal of Speech-Language Pathology: A American Speech-Language-Hearing Association, v. 19, n. 178, May, p. 178-195, 2010.

GOMES, C. G. S.; MENDES, E. G. Escolarização inclusiva de alunos com autismo na rede municipal de ensino de Belo Horizonte. Revista Brasileira de Educação Especial, n. 16, v. 3, p. $375-396,2010$.

LeBLANC, J. M. El Curriculum Funcional en la Educación de la Persona con Retardo Mental. Texto apresentado no Simpósio Internacional COANIL, Santiago, Chile, Novembro. Le Blanc, J. 1991.

LIRA, S. M. Escolarização de alunos com transtorno autista: histórias de sala de aula. Dissertação (Mestrado em Educação) apresentada ao Proped - programa de Pós-Graduação em Educação, da Universidade do Estado do Rio de Janeiro - Uerj, 2004.

LOURENÇO, G. F. Avaliação de um programa de formação sobre recursos de alta tecnologia assistiva e escolarização. Tese de Doutorado defendida no Programa de Pós-Graduação em Educação Especial. Universidade Federal de São Carlos. São Carlos, 2012.

MAYER-JOHNSON, R. ;WATT, S. M. The picture communication symbols. Stillwater, Minnesota: Mayer-Johnson Co., v. 1-3, 1981, 1985 e 1992.

MELO, S. C.. Autismo e educação: a dialética na inclusão. Dissertação (Mestrado em Educação) apresentada ao Proped - Programa de Pós-Graduação em Educação, da Universidade do Estado do Rio de Janeiro - Uerj, 2004.

NUNES, D. R. \& NUNES, L. R Efeitos dos procedimentos naturalísticos no processo de aquisição de linguagem através de sistema pictográfico em criança autista. In: L. R. Nunes 
(Org.). Favorecendo o desenvolvimento da comunicação em crianças e jovens com necessidade educacionais especiais. Rio de Janeiro: Dunya, 2003, p. 125-141.

NUNES, D. R. P; AZEVEDO, M. O; FREIRE, J. G. Comunicação alternativa em sala de aula: relatos de uma professora de alunos com autismo. In: NUNES, L. R. O. P, et al. (Org.). Compartilhando experiências: ampliando a comunicação alternativa. Marília, ABPEE, 2011.

NUNES, D, GOMES, R.. Interações comunicativas entre uma professora e um aluno com autismo na escola regular: uma proposta de intervenção. Educação e Pesquisa: Revista da Faculdade de Educação da Universidade de São Paulo (no prelo).

NUNES, L. R. Dando a voz através de imagens: comunicação alternativa para indivíduos com deficiência. Relatório do projeto de pesquisa financiado pela Faperj (Proc. 26/110235/2007), 2009.

NUNES, L. R. O. P. Linguagem e comunicação alternativa: uma introdução. IN: NUNES, L. R. O. P. (Org). Favorecendo o desenvolvimento da comunicação em crianças e jovens com necessidades especiais. Rio de Janeiro: Dunya, 2003.

OLIVEIRA, M. N. O uso da comunicação alternativa e ampliada por pessoa com deficiência múltipla e prejuízo severo de fala na educação de jovens e adultos: um estudo de caso. Tese de Doutorado defendida no Programa de Pós-Graduação em Educação, Universidade do Estado do Rio de Janeiro. Rio de Janeiro, 2010.

PAULA C.; RIBEIRO S.; FOMBONNE E.; MERCADANTE M. Brief Report: Prevalence of Pervasive Developmental Disorder in Brazil: A Pilot Study. J Autism Dev Disord, 1200-6, 2011.

PERISSINOTO, J. Linguagem da criança com autismo. In:J. PERISSINOTO, I. Q. MARCHESAN \& J. L. ZORZI (Orgs.). Conhecimentos essenciais para atender bem a criança com autismo. São José dos Campos: Pulso Editorial. 2003, p. 23-27.

PRIZANT, W.; RYDELL, P. Communication intervention issues for young children with autism spectrum disorders. In: A. M. Wetherby \& B. M. Prizant (Eds.), Children with autism spectrum disorders: A developmental, transactional perspective. (9). Baltimore, MD: Paul Brookes Publishing Company, 2000.

ROBERTSON, K.; CHAMBERLAIN, B.; KASARI, C. General education teachers' relationships with included students with autism. Journal of Autism and Developmental Disorders, v. 33, n. 2, p. 123-130, 2003.

RODRIGUEZ, I. R; SADAÑA, D.; MORENO, F. J. Support, inclusion, and special education: teachers' attitudes toward the education of students with autism spectrum disorders. Autism Research and Treatment. 2012, p. 1-8

SCHIRMER, C. R. A comunicação alternativa na escola: ensino, pesquisa e prática. In: NUNES, L. R. O. P, et al. (Org.). Compartilhando experiências: ampliando a comunicação alternativa. Marília, ABPEE, 2011.

SERRA, D. C. G. Entre a esperança e o limite: um estudo sobre a inclusão de alunos com autismo em classes regulares. Rio de Janeiro, 124p. Tese (Doutorado) - Departamento de Psicologia, Pontifícia Universidade Católica do Rio de Janeiro, Rio de Janeiro, 2008.

Revista Educação Especial | v. 26 | n. 47 | p. 587-602 | set./dez. 2013

Santa Maria 
SILVA, R. L. M, OLIVEIRA, A. I. A, SILVA, S. S. C; PONTES, F. A. R. A comunicação alternativa na interação professor-aluno com paralisia cerebral no contexto da sala comum. In: NUNES, L. R. O. P, et al. (Org.). Compartilhando experiências: ampliando a comunicação alternativa. Marília, ABPEE, 2011.

SIMPSON, R. Evidence-based practices and students with autism spectrum disorders. Focus on Autism and Other Developmental Disabilities, v. 20, n. 3, p. 140-149, 2005.

SUlZER-AZAROFF, B.; HOFFMAN, A. O.; HORTON, C.B.; BONDY, A.; FROST, L.. The Picture Exchange Communication System (PECS) What Do the Data Say? Focus on Autism and OtherDevelopmental Disabilities, v. 24, n. 2, p. 89-103, 2009.

TOMAZELLO, M. Origens cultuais da aquisição do conhecimento humano. São Paulo: Martins Fontes, 2003.

VON TETZCHNER, S. \& MARTINSEN, H. Words and strategies: Communication with young children who use aided language. In: von Tetzchner, S. E Jensen, M. H. (Eds.), Augmentative and alternative communication: European Perspective (p. 65-88). London, UK: Whurr. 1996.

WALTER, C. C.; CORREA NETTO, M. M.; NUNES, L. R. O. P. A Comunicação Alternativa e a Adaptação Pedagógica no Processo de Inclusão de Alunos com Autismo. In GLAT, R.; PLETSCH, M. (no prelo). Estratégias Educacionais Diferenciadas para Alunos com Necessidades Especiais . Rio de Janeiro, Eduerj/Proesp.

NUNES, L. R. O. P; TOGASHI, C. M. Quero conversar com você: comunicação alternativa para alunos com autismo no contexto escolar. In: Nunes, L. R. O. P, et al (Org.). Compartilhando experiências: ampliando a comunicação alternativa. Marília, ABPEE, 2011.

TOGASHI, C. M; LIMA, C. B. Comunicação alternativa para alunos com autismo no contexto escolar: o professor como agente comunicativo. In: IV Congresso Brasileiro de Comunicação Alternativa, Rio de Janeiro, 201l. CD-ROM do IV Congresso Brasileiro de Comunicação Alternativa. Rio de Janeiro: ABPEE, 2011.

Os efeitos da adaptação do PECS ao curriculum funcional natural em pessoas com autismo infantil. Dissertação de Mestrado. Programa de Pós-Graduação em Educação Especial, Universidade Federal de São Carlos, São Carlos, 2000.

\section{Notas}

${ }^{1}$ O Ensino Naturalístico rrefere-se a um modelo geral de intervenção em linguagem, que inclui: a) o uso de reforçadores indicados pelo aprendiz; b) o interesse da criança, que é considerado o fio condutor no processo de aprendizagem; c) as contingências do meio natural utilizadas para o aumento na frequência de emissões de respostas desejadas; d) a ênfase dada na competência comunicativa do educando em vez da linguagem per se; e) o ensino realizado durante atividades cotidianas em contextos e ambientes naturais (NUNES, NUNES, 2003)

${ }^{2}$ Projeto financiado pela Faperj (Proc. no 110.106/2011), aprovado pelo Edital no 21/2010 - Programa de Apoio à Melhoria do Ensino em Escolas Públicas Sediadas no Estado do Rio de Janeiro - 2011 (coordenado pela Professora. Cátia Walter).

${ }^{3}$ O PECS-Adaptado (WALTER, 2000) é um programa de Comunicação Alternativa por meio de intercâmbio de figuras baseado no PECS - Picture Exchange Communication Symbols (BONDY, FROSTY, 1994), que sofreu adaptações na sua forma de aplicação e registro, com estilo mais latino. As adaptações propostas foram fundamentadas na metodologia do Currículo Funcional Natural (LEBLANC, 1991) e apresentadas de forma 
diferenciada do programa original. Assim, o PECS-Adaptado é dividido em cinco fases de aplicação, sendo indicado para pessoas com autismo, ou com outros déficits severos na comunicação oral, que apresentam dificuldades para iniciar um diálogo de forma espontânea ou inabilidades sociais graves.

${ }^{4}$ Todos os nomes são fictícios.

${ }^{5}$ Reunião de Estudos é uma prática frequente realizada pela Secretaria Municipal de Educação do município do Rio de Janeiro, na qual os professores se encontram para estudos específicos sobre temas relacionados ao processo inclusivo e também para compartilhar novas práticas pedagógicas e seus resultados.

\section{Correspondência}

Cátia C. de F. Walter - Universidade do Estado do Rio de Janeiro, Rua S. Francisco Xavier 524 bloco F sala 12037, Maracanã, CEP: 20550-013 - Rio de Janeiro, Rio de Janeiro - Brasil.

E-mail: catiawalter@gmail.com - leilareginanunes@terra.com.br

Recebido em 28 de março de 2013

Aprovado em 21 de maio de 2013 
